\title{
MUDANÇAS NA URBANIZAÇÃO DE SANTO ESTEVÃO-BA: ANÁLISE SOCIOECONOMICO DA ÁREA CENTRAL.
}

\author{
Leniara da Conceição Silva \\ Graduanda em Geografia/Bolsista PIBIC Cnpq. \\ leniara.silvaa@gmail.com \\ Janio Santos \\ Doutor em Geografia, Professor Titular/DCHF-UEFS; \\ E-mail: janiosantos@yahoo.com.br
}

Palavras chave: Urbanização, Transformações, Centro, Santo Estevão

\section{INTRODUÇÃO}

Ao longo da história, o homem sempre adaptou-se ao espaço em que vivia, o que implicou em mudanças no seu meio e, consequentemente, alterações no modo de relacionar com os outros homens e com o seu espaço. Assim, tudo está propício a mudança, o que mostra que o espaço é dinâmico, e que as ações humanas fazem existir essa dinamicidade do espaço.

Seguindo esse aspecto, principalmente o espaço urbano no Brasil, ao longo das ultimas décadas, essas áreas vêm alterando os seus aspectos demográficos, sobretudo em função da migração do campo para a cidade. Suas formas espaciais alteram-se em velocidade muito grande, seguindo a lógica econômica, principalmente face aos agentes imobiliários, ao setor terciário, à expansão das filiais das empresas multinacionais de médio e grande portes, o que faz surgir um novo perfil de urbano, entrelaçado às contradições econômicas e socioespaciais.

Portanto, com base nessas transformações, nota-se que as cidades brasileiras, principalmente as médias e grandes, mas também as pequenas, cada vez mais têm a tendência de possuir padrões socioespaciais parecidos, ainda que dentro de suas diferencias. Ou seja, estruturas urbanas voltadas, principalmente, para uma única função: a urbanização econômica desenfreada e o terciário como "alavanca" para, em tese, alcançar o desenvolvimento urbano.

Dessa forma, foi o reconhecimento dessa dinâmica, ligada às transformações urbanas, as intencionalidades econômicas e aos efeitos de novas relações socioespaciais nas cidades pequenas, que fez surgir um olhar investigativo para Santo Estevão-BA e decorreu na elaboração deste projeto. A questão principal da pesquisa visa pensar o processo de urbanização e como esse implicou em mudanças, ao longo dos anos, no centro da cidade de Santo Estevão, o que influencia sua expansão urbana.

Face à localização da área urbana, próxima a segunda maior cidade da Bahia, que é Feira de Santana, e cortada por uma rodovia federal movimentada, que é BR 116, suas funcionalidades como pequeno centro sub-regional exerceram mudanças em sua urbanização, o que decorreu na materialização de processos no espaço urbano e em das ações socioeconômicas, como uma expansão urbana contínua, a produção de novas relações no espaço e um processo de urbanização muito mais acelerado, em relação as outras cidades pequenas situadas no seu entorno.

Santo Estevão é uma cidade do interior da Bahia, localizado no Território de Identidade Portal do Sertão, próxima a $53 \mathrm{~km}$ da segunda maior cidade baiana, Feira de Santana ( Ver Mapa 1). O município se estende em unidade territorial, segundo o IBGE (2010), de 362, $961 \mathrm{~km}^{2}$, com população estimativa, em 2015, de aproximadamente 53. 
193 habitantes (IBGE, 2015).

Dentre as cidades pequenas do Território do Portal do Sertão, Santo Estevão se destaca, em relação à algumas cidades próximas, como Antônio Cardoso, Ipecaetá e Rafael Jambeiro, face a economia e ao padrão demográfico. Esses municípios estão ligados economicamente à Santo Estevão, pois um fluxo significativo de pessoas migra frequentemente para a cidade, a fim de realizar compras e trabalhar, o que influencia, principalmente, no setor terciário e na atividade industrial, alterando assim a economia local.

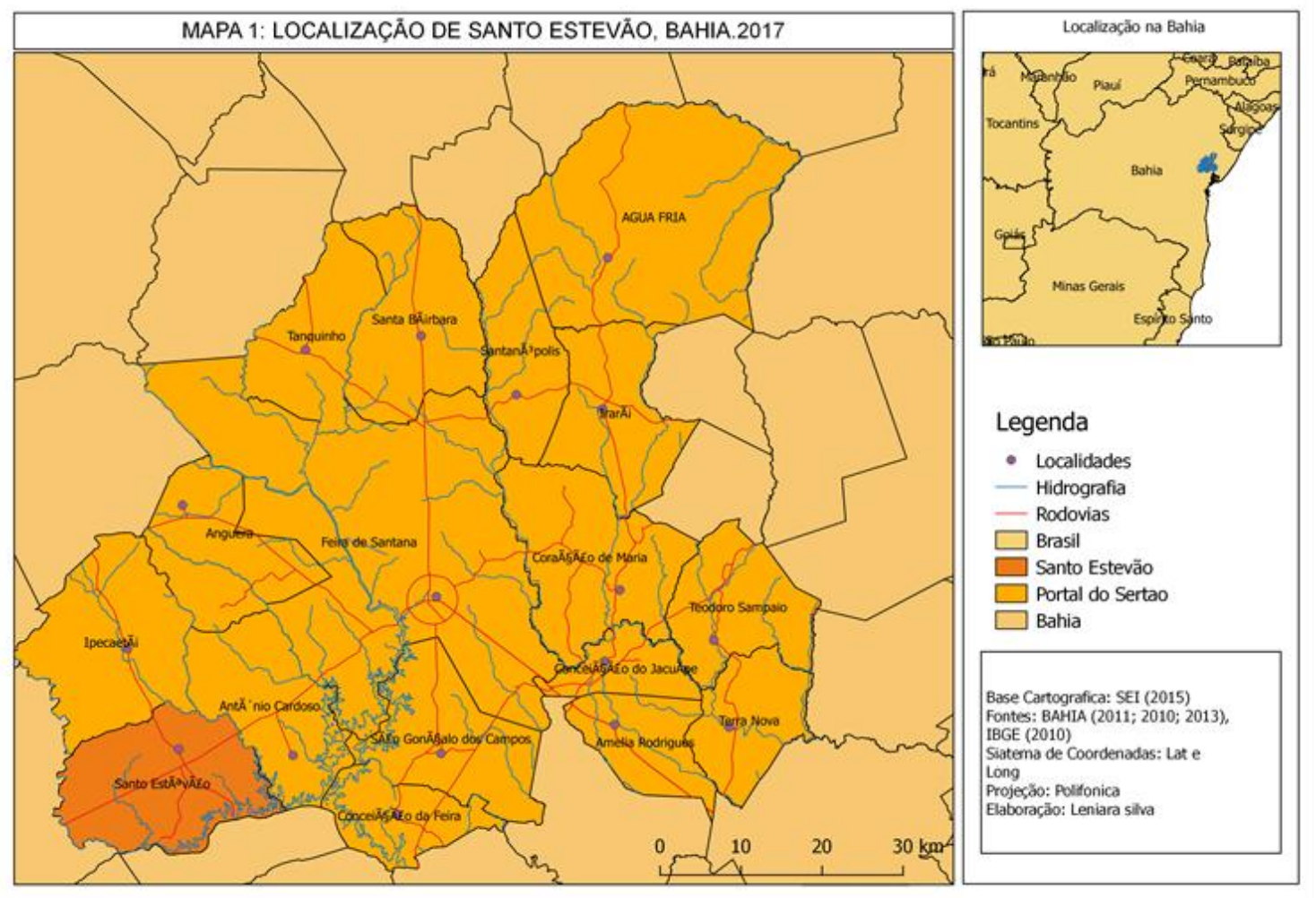

Dessa maneira, para entender a questão central, faz-se necessário analisar ainda como o fluxo migratório do campo para a cidade contribuiu para o processo de urbanização e até que ponto influenciou na área central; como as mudanças econômicas aconteceram ao longo das últimas décadas, tendo como um dos principais fatores a instalação de fabricas e filiais, o que fortaleceu o setor terciário no Centro da cidade; e discutir a ação e papel do poder público em promover mudanças socioespaciais e econômicas no Centro da cidade.

\section{METODOLOGIA}

A presente pesquisa é fruto de trabalhos e discussões envolvidos na Iniciação Cientifica, a qual possui caráter bibliográfico e estudo de campo, tendo como recorte o centro da cidade de Santo Estevão. Essa cidade que possui uma relação de vivência e pertencimento pela autora por habitar na mesma, e também por existir certa ausência de estudos sobre a área de estudo relacionando-a com a urbanização, o que fez surgir um olhar investigativo quanto às mudanças que apareceram na área advindas essencialmente pela expansão do processo de urbanização.

A parte procedimental da pesquisa iniciou com levantamento bibliográfico, com revisões teórico-conceituais de autores que estudam as cidades pequenas. Também 
foram pesquisados relatos antigos em jornais e revista e sites da própria Prefeitura Municipal de Santo Estevão, a fim de obter algumas informações que contribuam na análise das mudanças espaciais e econômicas ocorridas no centro; no PDDU, no Acervo Publico da cidade, o que oportunizou fazer um comparativo de situações antigos com as atuais, com o intuito de identificar os fatores que levaram as transformações ocorridas na mesma.

Foram aplicados 40 questionários com os comerciantes e 10 com os feirantes do Centro da cidade, com a finalidade de reunir informações sobre a formação desse, o perfil do comércio, o processo de expansão, as transformações, a participação do Estado e a utilização do mesmo. Foram feitas 4 entrevistas; 1 (uma) com o representante da Câmara de Dirigentes Lojistas (CDL), com o propósito de verificar as relações estabelecidas nesse Centro de Santo Estevão e a atuação da CDL; 1 (uma) com alguém da Prefeitura; e 2 (duas) com 2 moradores antigos do Centro, com objetivo de adquirir informações sobre o processo de formação desse. Por fim, depois de coletados todos os dados e informações necessárias, foram sistematizadas as análises dos resultados obtidos através de mapas da área estudada, gráficos e tabelas.

\section{RESULTADOS E DISCUSSÕES}

As características que tornam o centro de Santo Estevão como um espaço polarizador, tanto para os outros bairros da cidade, o campo e até mesmo as cidades vizinhas, fazem com que a área adquirisse certa particularidade em relação às demais.

Os recortes espaciais do município de Santo Estevão possuem certa hierarquia de importância. A cidade pode ser caracterizada como pólo microrregional, com influências que extrapolam os limites municipais, o que insere-se em função de sua dinâmica urbana com destaque entre outros municípios ao seu entorno. O centro, como espaço maior de concentração terciária, onde encontra-se os principais equipamentos e serviços urbanos, a qual atende as necessidades da população local e de municípios vizinhos, o que torna-se a área de grande relevância, face a sua função que se estabelece na vida da população que consome no espaço.

Dessa forma, o centro de Santo Estevão possui características próprias, um perfil de comércio e serviços diversificados, com uma feira livre relativamente forte, com maior fluxo de consumidores aos sábados e períodos festivos, o que dinamiza a área com a produção, circulação e consumo dos diferentes produtos encontrados no espaço.

O processo de expansão urbana fez existir essa dinamicidade nas outras áreas da cidade. Assim, é de fácil acesso encontrar mercadinhos, panificadoras, farmácias, lojas de confecções, lanchonetes, dentre outros, nos bairros mais afastados do centro. Dessa forma, percebe-se que, quando o espaço de maior vivência possui meios que possibilitem o não deslocamento constante para outras áreas, em busca de produtos os quais atendam as necessidades de determinada população, faz existir o consumo nas áreas próximas a sua residência, o que cria novos hábitos de consumo, lazer e em consequência, a reprodução do espaço.

\section{CONSIDERAÇÕES FINAIS}

Dessa forma, a cidade de Santo Estevão, considerada como cidade pequena, possui particularidades e processos que culminaram na formação do seu centro, acompanhados a expansão urbana no decorrer do tempo. As funcionalidades que o centro veio por estabelecer na cidade fizeram existir a concentração de uma diversidade de equipamentos urbanos na área central, o que possibilitou a mudança na forma de 
consumir em detrimento dos novos estabelecimentos fixados na área.

No que tange esse contexto, as análises possibilitaram a compreensão das espacialidades, funcionalidades e agentes modificadores da área estudada. $\mathrm{O}$ município de Santo Estevão enquanto microrregião de influência entre os demais municípios próximos; a cidade como espaço que polariza atividades econômicas; e o Centro como área que centraliza os principais equipamentos urbanos, com concentração de atividades do setor terciário a qual tem em sua história o processo de estruturação da cidade.

Diante de muitos fatores históricos e socioeconômicos, o centro de Santo Estevão pode ser caracterizado como espaço de origem que deu-se toda a estruturação da cidade, a qual apresentou um crescimento populacional contínuo acompanhado a transição econômica do município, dentre outros fatores, que, ao fortalecer o setor terciário, polarizou ainda mais em atividades e movimento de consumidores. O perfil de pessoas que fazem usos do espaço em questão é de característica mista, visto que, os produtos encontrados na feira livre da área e na atividade terciária atendem as necessidades da população local, do campo e da cidade e dos moradores oriundos de outros municípios vizinhos, como Antonio Cardoso, Ipecaetá e Rafael Jambeiro.

Assim, a relevância de analisar a cidade de Santo Estevão se baseou nas suas transformações e funcionalidade apresentada ao longo do tempo, cidade esta, inserida em uma rede urbana cujas mudanças das formas espaciais e econômicas em uma escala de tempo está ligado com o uso do espaço urbano, influenciados pelos processos e ações que contribuíram para o desenvolvimento e transição econômica da supracitada cidade. Entender a evolução da dinâmica do centro, desde a relação econômica, social e espacial, auxilia na compreensão do todo seu entorno: rede urbana, intraurbano, comércio, fluxos, campo etc., e as relações que fazem com que a cidade de Santo Estevão exerça influências e funções na vida de quem usam e produzem esses espaços.

Contudo, todos os fatores que influenciaram na urbanização e fortalecimento do Centro de Santo Estevão possuem em suas diferentes escalas a ação de agentes produtores deste espaço urbano. Nenhum processo existente na área aconteceu de maneira aleatória, o conjunto de ações dos diferentes setores sociais contribuíram para a materialização e fortalecimento desse centro. Espaço este presente na maioria das cidades, entrelaçados as contradições econômicas e espaciais, encontrados também nas cidades pequenas, porém, em escalas menos complexas.

\section{REFERÊNCIAS}

CORRÊA, Roberto Lobato. As pequenas cidades na confluência do urbano e do rural. In: Geousp, Espaço e Tempo, São Paulo, № 30, pp. 05 - 12, 2011.

INSTITUTO BRASILEIRO DE GEOGRAFIA E ESTATÍSTICA (IBGE). Censo Demográfico, 2010. Disponível em: <http://www.ibge.gov.br/censo2010/>. Acesso: 05 mai. 2017.

LOPES, D. M. F. Cidades pequenas são urbanas? O urbano possível. In: Bahia análise e dados, Salvador, v.19, n.2, p.395-492, jul/set. 2009

FRESCA, T.M. Centro locais e Pequenas Cidades: diferenças necessárias. MercatorRevista de Geografia da UFC, vol.9,n.20. 2010, p.75-81. Universidade Federal do Ceará- Fortaleza 2010. 